Research Article

\title{
Taming the Factor Zoo: New Evidence from China
}

\author{
Dongxu Chen $(\mathbb{D}$, Xieyang Shen $(\mathbb{D}$, and Tao Liu $(\mathbb{D})$ \\ School of Finance, Renmin University of China, Beijing, China \\ Correspondence should be addressed to Xieyang Shen; xieyang.shen@ruc.edu.cn
}

Received 25 July 2021; Revised 10 October 2021; Accepted 11 October 2021; Published 29 November 2021

Academic Editor: Dehua Shen

Copyright (C) 2021 Dongxu Chen et al. This is an open access article distributed under the Creative Commons Attribution License, which permits unrestricted use, distribution, and reproduction in any medium, provided the original work is properly cited.

We address the well-known "factor zoo" problem in the Chinese stock market. By replicating a generation of pricing factors, we verify the Liu-Stambaugh-Yuan four-factor model which subsumes other counterparts in the Chinese A-share market. We further construct a characteristic library and apply the double-selection LASSO approach to explore whether significant anomalies contribute to current pricing factors. We find that some anomalies indeed play a significant role in pricing cross-sectional returns, but the improvement to the Liu-Stambaugh-Yuan four-factor model is limited.

\section{Introduction}

Recent studies have proposed a series of factor models to price cross-sectional expected returns. As indicated by Cochrane [1], there exists a zoo of factors which can potentially explain expected stock returns. Searching for truly effective factors is a hot issue in asset pricing field. Once a new factor is constructed, researchers will evaluate whether it can provide incremental information by comparing with other mainstream factor models; see, for instance, works of Hou et al. [2], Racicot and Rentz [3], Racicot et al. [4], and Racicot et al. [5]. Hou et al. [2] show that the q-factor dominates all other pricing factors by various spanning tests. Racicot and Rentz [3]; Racicot et al. [4]; Racicot et al. [5] study some variants of the new Fama and French [6] model by using a new generalized method of moments estimator $\left(\mathrm{GMM}_{\mathrm{d}}\right)$ and find that only the market risk factor is the consistently significant factor. Furthermore, these papers also find that adding to the new Fama and French [6] model with the illiquidity factor of Pástor and Stambaugh [7] does not provide more explanatory power. Certainly, other researchers may put forward different opinions in the future, but studies in this field have one thing in common: they all depend on WRDS, a large and complete data library in the US market. However, it still remains a puzzle whether these powerful factors take effects in other emerging markets, such as the Chinese stock market.
As the second largest economy of the world, China has developed its capital market vigorously in recent years and the total market value exceeded 8 trillion dollars in the end of 2019. Even though Chinese stocks are getting more appealing to global investors, limited studies focus on asset pricing problems in the A-share market, especially about which factors drive cross-sectional Chinese stock returns. The political and economic environments are quite different from those in the US. Besides, China limits foreign investors to participating in its domestic stock market directly. Hence, the factor models in the US may not all work in China. We hope to determine the most effective factor models for A-share market in recent 20 years and explore whether there exist undiscovered latent pricing factors.

Using Chinese A-share data from July 2000 to December 2019, we start by replicating a generation of pricing factor models emerging in recent literature, including FamaFrench six-factor factor model (FF6, henceforth), Hou-Xue-Zhang q5-factor model (q5, henceforth), Stambaugh-Yuan four-factor model (SY4, henceforth), Daniel-Hirshleifer-Sun three-factor model (DHS-3, henceforth), and Liu-Stambaugh-Yuan four-factor model (LSY4, henceforth). Our paper independently constructs a database based on the work of Qiao [8] and Hou et al. [9]. We find LSY4 factors can generate a maximum Sharpe ratio of 2.16, significantly higher than other models. Differing from the US market, the investment factors hardly have any 
risk premiums for A-share stocks, regardless of whether we use the q-factor proposed by Hou et al. [2] or CMA factor proposed by Fama and French [10]. These two factors only generate the average return of $0.07 \%$ and $-0.10 \%$ across 20 years, respectively. Profitability factors, however, indeed show some significant risk premiums. The ROE factor of q5 is better than Fama's RMW, since the former is constructed with quarterly updated ROE rather than annually updated ROE. Consisting with this result, we find for SY 4 and DHS-3, which is based on mispricing and investor behaviors, respectively; only the parts related to profitability measures have significant risk premiums.

Next, we test the pricing power of these pricing models. Following Hou et al. [9], we construct 104 anomalies and obtain their value-weighted long-short return spreads. By calculating the alphas with respect to various pricing models, we show that LSY4 can explain up to 98 anomalies, far more than other models. Regardless of average alphas, average t-statistics, or Gibbons-Ross-Shanken statistics, LSY4 always achieves the lowest value, indicating its outstanding performance to price A-share stocks. When we turn to spanning tests, it is not surprising that LSY4 can explain all factors except for the postearnings-announcement drift (PEAD) factor. For example, the powerful q-factor recommended by Hou et al. [2] is totally subsumed and has a tiny alpha of $-0.06 \%(t=-0.38)$. However, PEAD survives from LSY4 with a significant alpha of $0.72 \%(t=3.35)$.

Finally, we explore whether other potential risk factors can be added into LSY4 in future research. In contrast to the previous risk premium perspective, we focus on SDF loadings in this section. We mainly adopt the double-selection LASSO approach proposed by Feng et al. [11] to evaluate the marginal contribution of other latent risk factors. This approach accounts for model selection mistakes in finite sample and tests the importance of a given factor beyond other benchmark factors. The factors we test here include significant anomalies in the A-share market found by Qiao [8] as well as anomalies with significant LHY4 alphas in the previous section. We choose the benchmark factors as the union of aforementioned pricing factors. The empirical result shows 8 out of 18 anomalies can provide incremental information, most of which describe trading frictions, such as idiosyncratic volatility per the FF3 model, daily trading volume, and volatility of turnover. As a robustness check, we also extend the number of benchmark factors and replace test portfolios, but the conclusion changes a little. However, we notice a slight improvement when we add these newly found factors into the LSY4 model. It indicates that current factor zoo is limited to price A-share stocks better than LSY4. We suppose future research should focus on constructing new characteristics to come up with new models.

The contribution of our paper is twofold. First, we fill the gap in asset pricing studies related to Chinese market. As we discussed before, few studies apply the forefront asset pricing models to Chinese market. Although the data library of A-share market is not comparable to WRDS, we suppose it is enough for us to conduct a thorough research. Unfortunately, most of researchers still focus on testing Fama-
French factors, ignoring the rapid development of literature in this field. On the contrary, these studies cannot even reach a consensus due to various samples. Examples of such studies include $\mathrm{Hu}$ et al. [12], Jiang et al. [13], and Cheung et al. [14]; some papers emphasize the importance of the value factor but others hold the opposite opinion. However, a recent research by Liu et al. [15] is remarkable, which can be regarded as a pioneer to explore factor models suitable for China. They construct a three-factor model using market return, size, and $E / P$ ratio and find their model plus a turnover factor can explain 10 significant anomalies in the Chinese market after excluding the 30\% smallest stocks. Nonetheless, this model still needs time to be universally accepted since it is newly published. Our paper inherits the work of Liu et al. [15] and will provide more robust evidences to support it.

Second, we conform to the trend in recent asset pricing literature that using machine learning techniques to search for latent pricing factors. As more and more factors are discovered, researchers are challenged by "multidimensionality" problem. Thus, a strand of literature takes advantage of variable selection approaches to screen effective factors. Representative works include Han et al. [16], Freyberger et al. [17], and Feng et al. [11]; all of which use LASSO regressions to exclude redundant factors. Inspired by their work, our paper applies LASSO to estimate SDF loadings based on a data library constructed by Qiao [8]. This author followed Hou et al. [9] and replicated 231 anomalies with Chinese stocks. Given some unique characteristics in the A-share market, the category and number of significant anomalies are really different from the US market. Thus, we pick out these significant anomalies and test whether they have contributions beyond the existing pricing factors using a double-selection LASSO approach. We hope our findings will inspire future asset pricing studies.

The rest of paper is organized as follows. Section 2 describes data and construction details of pricing factors. Section 3 reports the main empirical results of comparing asset pricing models, including explaining anomalies, spanning regression, and GRS test. Section 4 introduces the double-selection LASSO approach and shows its application on evaluating other potential risk factors. Section 5 is the conclusion.

\section{Data}

2.1. Data Source and Filters. We collect trading data and financial data from China Stock Market \& Accounting Research Database (CSMAR). Our sample period is from July 2000 to December 2019. We do not use data before June 2000 since the cash flow statements of A-share stocks begin at the end of 1997, and the calculation of some factors needs the data from previous consecutive quarters. In A-share market, income statement and cash flow statement only report flow data between two recent quarters. Thus, we recover stock values of accounting data by subtracting values from the prior quarter. Note that Chinese listed firms are required to release quarterly reports after 2002; we subtract flow data semiannually before 2002 . 
Our sample includes all A-shares, and we impose several filters to exclude stocks (1) of financial industry, (2) listed less than six months, (3) having less than 15 trading days last month, and (4) having less than 120 trading days in the past 12 months. In addition, referring to the views of Liu et al. [15], the smallest $30 \%$ stocks in the A-share market are possibly shell targets in reverse mergers, which contaminate stock returns. Thus, we also exclude the smallest 30\% stocks each month to avoid the shell value contamination.

2.2. Factor Pricing Models. This section briefly introduces the factor pricing models we are devoted to compare in our paper, including Fama-French six-factor factor model (FF6), Hou-Xue-Zhang q5-factor model (q5), Stambaugh-Yuan four-factor model (SY4), Daniel-Hirshleifer-Sun three-factor model (DHS-3), and Liu-Stambaugh-Yuan four-factor model (LSY4). The details to construct each factor are provided in the Supplementary Appendix (available (here)).

2.2.1. FF6 Model. Fama and French [6] propose their fivefactor model by adding two additional factors, CMA and RMW, into the well-known 3-factor model [18]. CMA is the average returns on stocks with low investment minus the average returns on stocks with high investment. RMW is the average returns on stocks with high operating profitability minus the average returns on stocks with low operating profitability. Fama and French [10] further add the sixth factor, UMD, to control the momentum effect found by Jegadeesh and Titman [19]. UMD is the difference of returns on winner and loser portfolios.

2.2.2. q5 Model. Hou et al. [20] propose the famous q-factor model and Hou et al. [2] augment it to the q5-factor model, whose factors include MKT, $R_{\text {me }}, R_{\text {roe }}, R_{\mathrm{ia}}$, and $R_{\text {eg }}$. In accordance with Fama-French factors, $R_{\text {me }}, R_{\text {roe }}$, and $R_{\mathrm{ia}}$ correspond to SMB, RMW, and CMA, respectively. However, they are derived from the q-theory instead of cashflow discounting. The fifth factor, $R_{\text {eg }}$, describes expected investment growth.

2.2.3. SY4 Model. Stambaugh and Yuan [21] do not construct their pricing factor by sorting stocks based on a specific characteristic; instead, they combine rankings of stocks with respect to 11 documented anomalies. The two new factors in addition to size and market factors, MGMT and PERF, are return spreads between underpriced stocks and overpriced stocks.

2.2.4. DHS-3 Model. Daniel et al. [22] propose a model that supplements CAPM with another two behavior factors. The financing factor FIN captures the long-horizon mispricing, which is induced by investors' overconfidence and exploited by managers' decisions to issue or repurchase equity. The postearnings' announcement drift factor PEAD captures the short-horizon mispricing, which is induced by investors' limited attention and underreaction to earnings' surprises.

2.2.5. LSY4 Model. Liu et al. [15] re-examine the size and value effect in China and construct new factors suitable for the A-share market. Compared to Fama and French [18], they replace the book-to-market ratio with earnings-to-price ratio and propose a new factor named VMG. Moreover, to subsume more anomalies, they add the fourth factor PMO based on one-month abnormal turnover. PMO represents the return spread between stocks about which investors are relatively pessimistic and stocks about which investors are relatively optimistic.

2.3. Test Anomalies. Hou et al. [9] have listed totally 447 anomalies published in top finance and accounting journals. However, one characteristic can construct several anomalies using different holding periods. Thus, their 447 anomalies are derived from 190 characteristics, which can be classified into 6 categories: momentum, value versus growth, investment, profitability, intangibles, and trading frictions. According to details disclosed in the online appendix of Hou et al. [9], our paper replicates 104 characteristics that are available and have fewest missing values in the A-share market. Qiao [8] also performs similar work but our characteristics accommodate theirs are more diverse in each category. We show their acronyms and definitions in Table 1.

One problem is how to combine characteristics with different frequencies. We need to merge the values of lowfrequency characteristics with monthly stock returns. There are three possible cases: (1) for annually updated characteristics, returns from July of year $t$ to June of year $t+1$ are matched with characteristics constructed in the December of year $t-1$; (2) for quarterly updated characteristics, returns in current month are matched with latest available characteristics, which are constructed with data published in the newest financial report; (3) for monthly updated characteristics, returns in current month are matched with characteristics constructed at the end of last month. Then, we sort each characteristic into 10 deciles and calculate the value-weighted decile returns for the next month. The deciles are rebalanced monthly. The anomaly returns are earned by holding a decile portfolio with respect to high expected returns and selling short a decile portfolio with respect to low expected returns.

\section{Comparing Factor Models}

3.1. Summary Statistics. We start by reporting the in-sample performance of individual factors. Table 2 displays some summary statistics for each factor model. The sample period is from July 2000 to December 2019. We find no FamaFrench factors are significant and its maximum Sharpe ratio is only 1.25 , which is the annualized Sharpe ratio of the tangency portfolio spanned by these factors. Specifically, the value effect measured by HML only derives the average return of $0.37 \%(t=1.43)$ per month. Other factors SMB, RMW, and UMD are even worse, whose returns are $0.35 \%$ $(t=1.40), 0.24 \%(t=1.11)$, and $0.23 \%(t=0.86)$, respectively. 
TABLE 1: List of characteristics. This table lists the acronyms, names, categories, and updating frequencies of 104 characteristics we consider in our empirical analysis. We build these characteristics using both trading and financial data from China Stock Market \& Accounting Research Database (CSMAR), accessible at Wharton Research Data Service (WRDS). The inclusion of characteristics, construction details, and classification follow Hou et al. [9], recognizing the discrepancies between accounting standards in China and US GAAP.

\begin{tabular}{|c|c|c|c|}
\hline Var & Definition & Category & Frequency \\
\hline abr & Cumulative abnormal returns around earnings announcement dates & Momentum & Quarterly \\
\hline abtur & Abnormal turnover & Trading frictions & Monthly \\
\hline age & Firm age & Intangible & Monthly \\
\hline alaq & Asset liquidity scaled by 1 -quarter-lagged total assets & Intangible & Quarterly \\
\hline almq & Asset liquidity scaled by 1 -quarter-lagged market value of assets & Intangible & Quarterly \\
\hline amq & Assets-to-market & Value versus growth & Quarterly \\
\hline ami & Absolute return-to-volume & Trading frictions & Monthly \\
\hline atoq & Return on quarterly assets turnover & Profitability & Quarterly \\
\hline beta & Market beta & Trading frictions & Monthly \\
\hline beta_ & Downside beta & Trading frictions & Monthly \\
\hline betad & The dimson beta & Trading frictions & Monthly \\
\hline betafp & The Frazzini-Pedersen beta & Trading frictions & Monthly \\
\hline blq & Quarterly book leverage & Profitability & Quarterly \\
\hline bm & Book-to-market equity & Value versus growth & Annually \\
\hline bmj & Book-to-june-end market equity & Value versus growth & Annually \\
\hline bmq & Quarterly book-to-market equity & Value versus growth & Quarterly \\
\hline cdi & Composite debt issuance & Investment & Annually \\
\hline cei & Composite debt issuance & Investment & Annually \\
\hline claq & Quarterly cash-based operating profits-to-lagged assets & Profitability & Quarterly \\
\hline cop & Cash-based operating profitability & Profitability & Annually \\
\hline cpq & Cash flow to price & Value versus growth & Quarterly \\
\hline cs & Coskewness & Trading frictions & Monthly \\
\hline cta & Cash to assets & Intangible & Annually \\
\hline ctoq & Capital turnover & Profitability & Quarterly \\
\hline cvd & Coefficient of variation of trading volume & Trading frictions & Monthly \\
\hline $\mathrm{cvt}$ & Coefficient of variation of share turnover & Trading frictions & Monthly \\
\hline dcoa & Changes in current operating assets & Investment & Annually \\
\hline dcol & Changes in current operating liabilities & Investment & Annually \\
\hline dgs & Change in gross margin minus change in sales & Intangible & Annually \\
\hline dmq & Debt to market & Value versus growth & Annually \\
\hline dnca & Changes in noncurrent assets & Investment & Annually \\
\hline dnco & Changes in net noncurrent operating assets & Investment & Annually \\
\hline dnoa & Changes in net operating assets & Investment & Annually \\
\hline dpia & Changes in ppe and inventory to assets & Investment & Annually \\
\hline droa & 4-quarter change in return on assets & Profitability & Quarterly \\
\hline droe & 4 -quarter change in return on equity & Profitability & Quarterly \\
\hline dsa & Change in sales minus change in accounts receivable & Intangible & Annually \\
\hline dsi & change in sales minus change in inventory & Intangible & Annually \\
\hline dss & Change in sales minus change in sg\&a & Intangible & Annually \\
\hline dtv & Trading volume & Trading frictions & Monthly \\
\hline dwc & Changes in net noncash working capital & Investment & Annually \\
\hline e6 & 6 -month residual momentum & Momentum & Monthly \\
\hline e11 & 11-month residual momentum & Momentum & Monthly \\
\hline ebpq & Enterprise book-to-price & Value versus growth & Annually \\
\hline emq & Enterprise multiple & Value versus growth & Annually \\
\hline epq & Earnings to price & Value versus growth & Quarterly \\
\hline etr & Effective tax rate & Intangible & Annually \\
\hline fpq & Failure probability & Profitability & Quarterly \\
\hline glaq & Gross profits-to-lagged assets & Profitability & Annually \\
\hline gpa & Gross profits to assets & Profitability & Annually \\
\hline ia & Investment to assets & Investment & Annually \\
\hline iaq & Quarterly investment to assets & Investment & Quarterly \\
\hline ir & Intangible return & Value versus growth & Annually \\
\hline isc & Idiosyncratic skewness per the CAPM & Trading frictions & Monthly \\
\hline isff & Idiosyncratic skewness per the FF3 model & Trading frictions & Monthly \\
\hline isq & Idiosyncratic skewness per the q-factor model & Trading frictions & Monthly \\
\hline iv & Idiosyncratic volatility & Trading frictions & Monthly \\
\hline
\end{tabular}


TABLE 1: Continued.

\begin{tabular}{|c|c|c|c|}
\hline Var & Definition & Category & Frequency \\
\hline ivq & Idiosyncratic volatility per the $\mathrm{q}$-factor model & Trading frictions & Monthly \\
\hline ivff & Idiosyncratic volatility per the FF3 model & Trading frictions & Monthly \\
\hline ivg & Inventory growth & Investment & Annually \\
\hline kzq & Financial constraints (the Kaplan-Zingales index) & Intangible & Quarterly \\
\hline mdr & Maximum daily return & Trading frictions & Monthly \\
\hline me & Market equity & Trading frictions & Annually \\
\hline ndpq & Quarterly net debt to price & Value versus growth & Quarterly \\
\hline noa & Net operating assets & Investment & Annually \\
\hline nopq & Quarterly net payout yield & Value versus growth & Quarterly \\
\hline nsi & Net stock issues & Investment & Annually \\
\hline ocpq & Operating cash flow to price & Value versus growth & Quarterly \\
\hline olaq & Operating profits-to-lagged assets & Profitability & Quarterly \\
\hline oleq & Operating profits-to-lagged equity & Profitability & Quarterly \\
\hline olq & Quarterly operating leverage & Intangible & Quarterly \\
\hline opa & Operating profits to assets & Profitability & Annually \\
\hline ope & Operating profits to equity & Profitability & Annually \\
\hline opq & Quarterly payout yield & Value versus growth & Quarterly \\
\hline $\mathrm{o}$ & Ohlson's $o$-score & Profitability & Quarterly \\
\hline pmq & Quarterly return on profit margin & Profitability & Quarterly \\
\hline poa & Percent operating accruals & Investment & Annually \\
\hline pps & Share price & Trading frictions & Monthly \\
\hline ra25 & Seasonality (average return over months $\mathrm{t}-24, \mathrm{t}-36, \mathrm{t}-48$, and $\mathrm{t}-60$ ) & Intangible & Monthly \\
\hline rn25 & Seasonality (average return from month $\mathrm{t}-60$ to $\mathrm{t}-13$ ) & Intangible & Monthly \\
\hline rla & Seasonality (return in month $\mathrm{t}-12$ ) & Intangible & Monthly \\
\hline rln & Seasonality (average return from month $\mathrm{t}-11$ to $\mathrm{t}-1$ ) & Intangible & Monthly \\
\hline r6 & Prior 6-month returns & Momentum & Monthly \\
\hline r11 & Prior 11-month returns & Momentum & Monthly \\
\hline rev & Reversal & Value versus growth & Monthly \\
\hline rnaq & Return on net operating assets & Profitability & Annually \\
\hline roa & Return on assets & Profitability & Quarterly \\
\hline roe & Return on equity & Profitability & Quarterly \\
\hline rs & Revenue surprises & Momentum & Quarterly \\
\hline sgq & Sales growth & Value versus growth & Annually \\
\hline size & Firm size & Trading frictions & Monthly \\
\hline $\mathrm{spq}$ & Sales to price & Value versus growth & Quarterly \\
\hline $\mathrm{sr}$ & 5-year sales growth rank & Value versus growth & Annually \\
\hline srev & Short-term reversal & Trading frictions & Monthly \\
\hline sue & Standardized unexpected earnings & Momentum & Quarterly \\
\hline tail & Tail risk & Trading frictions & Monthly \\
\hline $\operatorname{tanq}$ & Tangibility & Intangible & Annually \\
\hline tbiq & Taxable income-to-book income & Profitability & Quarterly \\
\hline tes & Tax expense surprises & Momentum & Quarterly \\
\hline ts & Total skewness & Trading frictions & Monthly \\
\hline tur & Share turnover & Trading frictions & Monthly \\
\hline tv & Total volatility & Trading frictions & Monthly \\
\hline wwq & The whited-Wu index & Intangible & Quarterly \\
\hline $\mathrm{zq}$ & Altman's $z$-score & Profitability & Quarterly \\
\hline
\end{tabular}

Consistent with Liu et al. [15], we see the investment factor CMA is very weak in the A-share market, since its mean return is even negative. As a result, the q-factors showing strong explanative power in the US market does not have enough risk premiums as we expected. Similar to Fama's CMA, the investment factor $R_{\text {ia }}$ also has a mean return approaching to zero, about $0.07 \%(t=0.49)$ per month. And the addition of expected growth factor $R_{\text {eg }}$ is likewise useless; it only yields a tiny premium of $0.18 \%(t=0.85)$. However, we find the profitability factor $R_{\text {roe }}$ is much stronger than RMW, with an average return of $0.87 \%(t=4.11)$ versus $0.24 \%(t=1.11)$. Although both of them are return spreads sorted by firms' ROE, $R_{\text {roe }}$ uses quarterly data, and its value is updated every three months. That indicates stocks in the A-share market are more sensitive to recent changes of earnings, and firms with high profitability indeed generate substantially higher stock returns, which is exactly the main conclusion of Jiang et al. [13].

This fact can also be seen from anomaly-based factors. We find the maximum Sharpe ratio for Stambaugh and Yuan's mispricing factors is only about 0.73 annually, the lowest in Table 2. As we have listed in the Supplementary Appendix, MGMT includes various investment measures, whereas PERF includes various profitability measures. Thus, 
TABLE 2: Summary statistics of pricing factors. This table shows means, standard deviations, $t$-statistics, skewness, kurtosis, and Jarque-Bera statistic of each pricing factor and the maximum Sharpe ratio achievable from each factor model. The sample period is from July 2000 to December 2019. The first to last row correspond to the Fama-French 6-factor model [10], the Hou-Xue-Zhang q5-factor model [2], the Stambaugh-Yuan 4-factor model [21], the Daniel-Hirshleifer-Sun 3-factor model [22], and the Liu-Stambaugh-Yuan 4-factor model [15].

\begin{tabular}{|c|c|c|c|c|c|c|c|c|}
\hline \multicolumn{2}{|c|}{ Pricing factors } & Mean (\%) & Std. dev (\%) & $t$ value & Skewness & Kurtosis & J-B stat. & Sharpe ratio \\
\hline \multirow{6}{*}{ FF6 } & $\mathrm{MKT}$ & 0.50 & 8.10 & 0.94 & -0.23 & 4.06 & 19.93 & \multirow{6}{*}{1.25} \\
\hline & SMB & 0.35 & 3.78 & 1.40 & -0.29 & 4.60 & 28.84 & \\
\hline & HML & 0.37 & 4.01 & 1.43 & -0.18 & 7.02 & 163.34 & \\
\hline & RMW & 0.24 & 3.28 & 1.11 & 0.25 & 5.85 & 83.45 & \\
\hline & CMA & -0.10 & 2.47 & -0.61 & 0.19 & 5.48 & 62.98 & \\
\hline & UMD & 0.23 & 4.05 & 0.86 & -0.47 & 4.38 & 27.71 & \\
\hline \multirow{5}{*}{ Q-5 } & MKT & 0.50 & 8.10 & 0.94 & -0.23 & 4.06 & 19.93 & \multirow{5}{*}{1.72} \\
\hline & $R_{\mathrm{me}}$ & 0.55 & 3.39 & 2.47 & -0.21 & 5.38 & 58.31 & \\
\hline & $R_{\mathrm{ia}}$ & 0.07 & 2.05 & 0.49 & 0.22 & 3.62 & 5.83 & \\
\hline & $R_{\text {roe }}$ & 0.87 & 3.25 & 4.11 & 0.20 & 4.34 & 19.68 & \\
\hline & $R_{\mathrm{eg}}$ & 0.18 & 3.32 & 0.85 & 0.07 & 6.78 & 143.20 & \\
\hline \multirow{4}{*}{ SY-5 } & MKT & 0.50 & 8.10 & 0.94 & -0.23 & 4.06 & 19.93 & \multirow{4}{*}{0.73} \\
\hline & SMB & 0.44 & 4.50 & 1.50 & -0.62 & 9.35 & 418.85 & \\
\hline & MGMT & 0.01 & 3.06 & 0.07 & 0.32 & 9.89 & 479.14 & \\
\hline & PERF & 0.63 & 4.53 & 2.12 & 0.36 & 4.36 & 23.72 & \\
\hline \multirow{3}{*}{ DHS-3 } & MKT & 0.50 & 8.10 & 0.94 & -0.23 & 4.06 & 19.93 & \multirow{3}{*}{1.23} \\
\hline & PEAD & 0.98 & 3.01 & 4.97 & -0.13 & 3.46 & 2.80 & \\
\hline & FIN & 0.12 & 2.17 & 0.84 & -0.48 & 9.42 & 420.95 & \\
\hline \multirow{4}{*}{ LSY4 } & MKT & 0.50 & 8.10 & 0.94 & -0.23 & 4.06 & 19.93 & \multirow{4}{*}{2.16} \\
\hline & SMB & 0.52 & 4.01 & 2.00 & 0.06 & 4.77 & 20.31 & \\
\hline & VMG & 1.09 & 3.29 & 5.04 & 0.12 & 4.45 & 7.04 & \\
\hline & PMO & 0.81 & 3.35 & 3.68 & -0.82 & 9.78 & 401.52 & \\
\hline
\end{tabular}

it is not surprising that the average return of MGMT is nearly zero $(0.01 \%$ and $t=0.07)$, but the average return of PERF is significantly positive $(0.63 \%$ and $t=2.12)$. Likewise, we see for the DHS-3, the postearnings-announcement drift (PEAD) factor, which is constructed by anomalies reflecting earnings' surprises, earns on average $0.98 \%(t=4.97)$ per month. However, the financing factor FIN only delivers a premium of $0.12 \%(t=0.84)$. At last, LSY -4 factors show the most significant risk premiums, with a maximum Sharpe ratio of 2.16. VMG effectively reflects the value effect; it earns an average return of $1.09 \%(t=5.04)$, the highest among all factors. The sentiment factor PMO is also profitable and yields on average $0.81 \%(t=3.68)$.

Interestingly, Table 2 also shows each pricing factor and illustrates the characteristic of leptokurtosis and fat tail, since all values of kurtosis are greater than 3 . This fact is consistent with Jarque-Bara statistics, since we find the null hypotheses of the time series following normal distribution are rejected for all factors at the $1 \%$ significance level, except for $R_{\mathrm{ia}}$ and PEAD.

Table 3 reports the correlation matrix of all pricing factors. To make it clear, SMB in Table 3 corresponds to the size factor in LSY4. We are mainly interested about how LSY4 factors are related to the others. Not surprisingly, SMB is nearly equivalent to the size factor in the q-factor model, with a correlation of 0.92 . The value factor VMG is highly correlated with profitability factors. It has a correlation of 0.68 with RMW and 0.81 with $R_{\text {roe }}$. It is because VMG is derived from earnings-to-price ratio, which is a comprehensive characteristic reflecting the value and expected earnings' growth of a stock. The conventional value factor $\mathrm{HML}$ is not closely related to VMG. For sentiment factor
PMO, we find few factors are highly correlated with it. The closest factor is HML, only with a correlation of -0.27 . That indicates other factors cannot subsume the premium of turnover effect, and thus, it is reasonable to add it into the model to price A-share stocks.

3.2. Explaining Anomalies. In Table 4, we regress 104 anomaly returns on various factor models, to investigate the performance of factor models in explaining anomalies. Columns 1-3 report the mean return, standard deviation, and $t$-statistic for each anomaly over the period from July 2000 to December 2019. For these unadjusted raw returns, we find 42 of 104 anomalies are significant (shown in bold). That indicates mispricing is a little severe in the A-share market, and strategies based on mispricing can earn significant profits. Next, columns $4-8$ correspond to $t$-statistics of alphas controlling for various pricing factors, given Newey-West adjustments over 12-month lag. Surprisingly, it shows for models proposed from the US market, which are displayed in columns 4-7, are nearly useless: there are still 49,43,55, and 39 alphas with $t$ statistics higher than 1.96, respectively. In other words, significant anomalies can hardly be eliminated by these four models. In comparison, LSY4 has great effect on explaining these anomalies, with only six of 104 significant alphas, including Dimson beta (betad), one measure of seasonality (rn25), two measures of idiosyncratic skewness per different models (isff and isq), cumulative abnormal returns around earnings announcement dates (abr), and 6month residual momentum (e6). 
TABLE 3: Correlation matrix of pricing factors. This table displays the correlation matrix of mainstream pricing factors. The sample period is from July 2000 to December 2019. MKT, SMB, VMG, and PMO are market, size, value, and turnover factors in the Liu-Stambaugh-Yuan 4factor model [15]. HML, RMW, CMA, and UMD are value, profitability, investment, and momentum factors in the Fama-French 6-factor model [10]. $R_{\mathrm{me}}, R_{\mathrm{ia}}, R_{\mathrm{roe}}$, and $R_{\mathrm{eg}}$ are size, investment, profitability, and expected growth factor in the Hou-Xue-Zhang q5-factor model [2]. MGMT and PERF are two mispricing factors in the Stambaugh-Yuan 4-factor model [21]. PEAD and FIN are two long-short horizon factors in the Daniel-Hirshleifer-Sun 3-factor model [22].

\begin{tabular}{|c|c|c|c|c|c|c|c|c|c|c|c|c|c|c|c|c|}
\hline & SMB & MKT & VMG & HML & RMW & $\mathrm{CMA}$ & UMD & PMO & $R_{\mathrm{me}}$ & $R_{\mathrm{ia}}$ & $R_{\text {roe }}$ & $R_{\mathrm{eg}}$ & MGMT & PERF & FIN & PEAD \\
\hline SMB & 1.00 & & & & & & & & & & & & & & & \\
\hline MKT & 0.23 & 1.00 & & & & & & & & & & & & & & \\
\hline VMG & -0.63 & -0.31 & 1.00 & & & & & & & & & & & & & \\
\hline HML & -0.41 & 0.04 & 0.38 & 1.00 & & & & & & & & & & & & \\
\hline RMW & -0.62 & -0.35 & 0.68 & -0.10 & 1.00 & & & & & & & & & & & \\
\hline CMA & 0.21 & 0.01 & -0.12 & 0.54 & -0.59 & 1.00 & & & & & & & & & & \\
\hline UMD & -0.37 & -0.19 & 0.28 & -0.18 & 0.49 & -0.30 & 1.00 & & & & & & & & & \\
\hline PMO & 0.04 & -0.23 & -0.01 & -0.27 & 0.11 & -0.18 & 0.08 & 1.00 & & & & & & & & \\
\hline$R_{\mathrm{me}}$ & 0.92 & 0.21 & -0.62 & -0.52 & -0.49 & 0.05 & -0.15 & 0.08 & 1.00 & & & & & & & \\
\hline$R_{\mathrm{ia}}$ & 0.03 & -0.07 & 0.12 & 0.55 & -0.37 & 0.89 & -0.15 & -0.09 & -0.08 & 1.00 & & & & & & \\
\hline$R_{\text {roe }}^{\text {id }}$ & -0.54 & -0.32 & 0.81 & -0.01 & 0.79 & -0.34 & 0.57 & 0.08 & -0.40 & -0.05 & 1.00 & & & & & \\
\hline$R_{\mathrm{eg}}$ & -0.33 & 0.00 & 0.34 & 0.85 & -0.18 & 0.58 & -0.24 & -0.21 & -0.48 & 0.60 & -0.03 & 1.00 & & & & \\
\hline MGMT & 0.17 & -0.01 & -0.08 & 0.34 & -0.40 & 0.71 & -0.20 & -0.03 & 0.08 & 0.64 & -0.19 & 0.43 & 1.00 & & & \\
\hline PERF & -0.31 & -0.31 & 0.46 & -0.34 & 0.69 & -0.43 & 0.73 & 0.17 & -0.11 & -0.24 & 0.75 & -0.38 & -0.19 & 1.00 & & \\
\hline FIN & -0.11 & 0.05 & 0.13 & 0.32 & -0.02 & 0.29 & -0.05 & -0.10 & -0.14 & 0.36 & 0.07 & 0.32 & 0.34 & -0.06 & 1.00 & \\
\hline PEAD & -0.26 & -0.24 & 0.37 & -0.05 & 0.39 & -0.12 & 0.49 & 0.02 & -0.12 & 0.04 & 0.52 & -0.03 & -0.03 & 0.50 & 0.08 & 1.00 \\
\hline
\end{tabular}

Table 5 further reports other statistics reflecting explaining power of pricing models. Again, we use these 104 anomalies as test assets. Average alpha is the absolute mean of 104 alphas with respect to each model, and average $t$ is the absolute mean of corresponding $t$-statistics. Following Shanken [23], pricing errors are computed as

$$
\Delta=\alpha / \Sigma^{-1} \alpha,
$$

where $\alpha$ is the vector of alpha and $\Sigma$ is the covariance matrix of residuals for each factor model. We also perform the wellknown GRS test proposed by Shanken et al. [24] to show whether alphas of 104 anomalies are jointly zero. Generally speaking, it seems that LSY4 has great advantage over other counterparts. It generates the smallest average absolute alpha of $0.31 \%$ as well as average absolute $t$-statistic of only 1.00 . Its pricing error is the second lowest with the value of 3.65, slightly higher than the q-factor model (3.61). As for GRS test, we find all models reject the null hypothesis that alphas are jointly zero. It is not surprising since, as Table 4 shows, no factor model can accommodate all anomalies. However, LSY4 derives the smallest GRS statistic.

3.3. Spanning Regressions. So far, we have shown the strong pricing power of the LSY4 model. Another key question is whether LSY4 can price factors of other models, which matters for model comparison. In this section, we regress FF6 factors, q5 factors, SY4 factors, and DHS-3 factors on LSY4 factors in turn, to show whether LSY4 factors can explain their risk premiums. Table 6 displays the results. From the Durbin-Watson statistics in the last column, we realize we cannot reject the hypothesis that residuals may suffer from autocorrelations. Thus, we adjust standard errors of regression coefficients using the Newey and West [25] correction with three lags. We find, except for PEAD and
$R_{\text {me }}$, other alphas are insignificant with the specification of the LSY4 model, indicating corresponding factors are accommodated by LSY4 factors. For example, the alpha of powerful q-factor $R_{\text {roe }}$ is only $0.07 \%(t=0.48)$, and the investment premium $R_{\mathrm{ia}}$ is further reduced to $-0.06 \%$ $(t=-0.41)$. On the contrary, PEAD survives from the LSY4 model with a highly significant alpha of $0.71 \%(t=3.35)$. This fact consists with Table 4, since, as we have illustrated previously, PEAD is constructed with four-day cumulative abnormal return (abr), which cannot be explained by LSY4 factors. We also report two GRS statistics. We can hardly reject the null that all alphas are jointly equal to zero $(\mathrm{GRS}=2.23)$, but once excluding PEAD, the GRS statistic declines to 1.47 immediately.

\section{Exploring New Factors}

In this section, we will explore whether there any significant anomalies can serve as latent pricing factors which can be added into the current LSY4 model. We mainly depend on the double-selection LASSO approach proposed by Feng et al. [11] and evaluate marginal contributions of a series of new factors beyond existing factors. We start with a brief introduction of this methodology and then report our findings.

4.1. Double-Selection LASSO. In asset pricing theory, the ability of a given factor to explain asset prices is reflected in its stochastic discount factor (SDF) loadings, as discussed by Cochrane [26] and Ferson [27]. Typically, we assume the stochastic discount factor has the following linear specification:

$$
m_{t}:=\gamma_{0}^{-1}-\gamma_{0}^{-1} \lambda_{v} v_{t}:=\gamma_{0}^{-1}\left(1-\lambda_{g} g_{t}-\lambda_{h} h_{t}\right)
$$


TABLE 4: Anomalies by univariate characteristic sorting. This table displays the return properties of anomalies constructed by sorting on each of the 104 characteristics over the whole sample of July 2000 to December 2019. With monthly rebalancing, we sort all stocks by individual characteristics into 10 deciles, form value-weighted portfolio within each decile, and build a long-short spread portfolio using decile ten and one. For each portfolio, we report the monthly return means, standard deviations, and $t$-statistics in columns labeled "Mean," "Std. dev," and "t-Raw." We also use various factor models to explain these anomalies and report corresponding $t$-statistics of alphas with Newey-West adjustment over 12 monthly lags, including the Fama-French 6-factor model [10], the Hou-Xue-Zhang q5-factor model [2], the Stambaugh-Yuan 4-factor model [21], the Daniel-Hirshleifer-Sun 3-factor model [22], and the Liu-Stambaugh-Yuan 4-factor model [15], in columns "t-FF6," "t-Q5," "t-SY4," "t-DHS3," and "t-LSY4," respectively. Bold types denote values that are statistically significant at 95\% confidence.

\begin{tabular}{|c|c|c|c|c|c|c|c|c|}
\hline Anomaly & $\begin{array}{c}(1) \\
\text { Mean }(\%)\end{array}$ & $\begin{array}{c}(2) \\
\text { Std. dev (\%) }\end{array}$ & $\begin{array}{c}3) \\
\text { t-Raw }\end{array}$ & $\begin{array}{c}(4) \\
\mathrm{t}-\mathrm{FF} 6\end{array}$ & $\begin{array}{c}\text { (5) } \\
t-Q 5\end{array}$ & $\begin{array}{c}(6) \\
t-S Y 4\end{array}$ & $\begin{array}{c}(7) \\
\mathrm{t}-\mathrm{DHS} 3\end{array}$ & $\begin{array}{c}(8) \\
\text { t-LSY4 }\end{array}$ \\
\hline abr & 0.85 & 4.74 & 2.92 & 2.75 & 1.89 & 2.97 & 0.09 & 2.41 \\
\hline abtur & 1.12 & 5.91 & 3.92 & 3.98 & 3.5 & 3.15 & 5.35 & 0.16 \\
\hline age & 0.01 & 4.07 & 0.05 & 0.77 & 0.52 & 0.8 & 0.92 & 0.5 \\
\hline alaq & 0.86 & 4.21 & 3.34 & 3.59 & 1.71 & 2.2 & 2.55 & 1.33 \\
\hline almq & 0.71 & 6.40 & 2 & 2.78 & 5.41 & 5.74 & 2.96 & 1.24 \\
\hline ami & 0.81 & 6.63 & 1.62 & 3.89 & 1.96 & 1.27 & 2.5 & 0.59 \\
\hline amq & 0.52 & 7.34 & 1.23 & 1.46 & 4.17 & 5.1 & 3.28 & 0.4 \\
\hline atoq & 0.90 & 3.78 & 2.96 & 4.03 & 2.24 & 2.66 & 2.4 & 1.69 \\
\hline beta & 0.53 & 6.39 & 1.46 & 1.91 & 0.92 & 1.82 & 0.27 & 0.14 \\
\hline beta_ & 0.26 & 6.57 & 0.67 & 1.86 & 0.98 & 1.78 & 0.31 & 1.27 \\
\hline betad & 1.05 & 5.91 & 2.61 & 2.19 & 2.6 & 3.05 & 3.09 & 2.57 \\
\hline betafp & 0.64 & 6.98 & 1.68 & 2.28 & 0.95 & 1.69 & 0.47 & 0 \\
\hline blq & 0.05 & 5.11 & 0.14 & 0.53 & 0.82 & 2.13 & 0.35 & 0.32 \\
\hline bmj & 0.21 & 4.87 & 0.62 & 0.44 & 1.6 & 2.78 & 1.07 & 0.32 \\
\hline bmq & 0.59 & 7.22 & 1.43 & 2.22 & 4.7 & 5.21 & 3.43 & 0.36 \\
\hline $\mathrm{cdi}^{1}$ & 0.04 & 3.44 & 0.18 & 0.09 & 1.15 & 0.91 & 0.64 & 0.69 \\
\hline cei & 0.22 & 4.16 & 0.89 & 1.24 & 0.31 & 2.2 & 0.24 & 0.27 \\
\hline claq & 0.15 & 4.51 & 0.56 & 0.28 & 0.09 & 1.17 & 0.72 & 0.29 \\
\hline cop & 0.00 & 4.77 & 0 & 1.14 & 0.47 & 0.56 & 0.31 & 0.76 \\
\hline cpq & 0.66 & 4.00 & 2.32 & 2.34 & 2.61 & 3.51 & 3.35 & 0.45 \\
\hline cs & 0.15 & 5.30 & 0.5 & 0.17 & 0.27 & 1.54 & 0.09 & 1.11 \\
\hline cta & 0.54 & 5.07 & 2 & 2.29 & 0.5 & 0.62 & 0.66 & 0.03 \\
\hline ctoq & 0.63 & 4.08 & 2.64 & 3.31 & 1.52 & 2.27 & 1.74 & 1.08 \\
\hline cvd & 0.95 & 4.95 & 2.95 & 3.68 & 1.82 & 2.25 & 1.42 & 1.16 \\
\hline $\mathrm{cvt}$ & 0.65 & 4.98 & 1.8 & 2.23 & 1.28 & 1.02 & 0.52 & 0.94 \\
\hline dcoa & 0.12 & 3.72 & 0.57 & 1.06 & 0.52 & 1 & 1.58 & 0.17 \\
\hline dcol & 0.02 & 2.96 & 0.1 & 0.07 & 0.42 & 0.53 & 0.45 & 0.27 \\
\hline dgs & 0.02 & 3.11 & 0.14 & 1.65 & 1.57 & 0.29 & 1.35 & 1.14 \\
\hline $\mathrm{dmq}$ & 0.24 & 5.98 & 0.61 & 0.19 & 2.43 & 3.3 & 1.79 & 0.16 \\
\hline dnca & 0.26 & 3.06 & 1.32 & 1.44 & 0.58 & 1.87 & 2.08 & 0.13 \\
\hline dnco & 0.14 & 2.70 & 0.77 & 0.35 & 0.64 & 1.3 & 1.37 & 0.45 \\
\hline dnoa & 0.23 & 3.35 & 1.04 & 0.96 & 0.72 & 1.48 & 1.17 & 0.17 \\
\hline dpia & 0.07 & 3.37 & 0.36 & 0.29 & 0.7 & 0.25 & 1.22 & 1.22 \\
\hline droa & 0.98 & 4.24 & 3.96 & 5.66 & 1.18 & 3.39 & 2.48 & 0.83 \\
\hline droe & 1.10 & 4.15 & 4.98 & 6.32 & 1.34 & 4.46 & 3.11 & 1.12 \\
\hline dsa & 0.37 & 2.62 & 2.19 & 2.26 & 1.58 & 1.83 & 1.58 & 1.25 \\
\hline dsi & 0.16 & 2.41 & 1.02 & 0.63 & 0.33 & 0.76 & 0.69 & 0.28 \\
\hline dss & 0.17 & 2.71 & 0.88 & 1.81 & 2 & 0.84 & 1.08 & 1.86 \\
\hline $\mathrm{dtv}$ & 0.84 & 6.12 & 1.79 & 3.61 & 1.39 & 1.55 & 2.6 & 0.08 \\
\hline dwc & 0.09 & 3.03 & 0.55 & 0.43 & 0.51 & 0.73 & 0.11 & 0.33 \\
\hline e11 & 0.40 & 4.72 & 1.07 & 0.84 & 0.2 & 0.68 & 0.28 & 1.37 \\
\hline e6 & 0.47 & 4.80 & 1.52 & 1.52 & 0.92 & 1.23 & 0.38 & 2.48 \\
\hline ebpq & 1.15 & 7.53 & 2.88 & 3.22 & 5.4 & 5 & 3.32 & 1.8 \\
\hline emq & 1.34 & 6.21 & 3.5 & 5.02 & 3.17 & 5.41 & 2.41 & 0.5 \\
\hline epq & 1.27 & 6.07 & 3.53 & 4.88 & 2.84 & 5.22 & 2.48 & 0.32 \\
\hline etr & 0.28 & 3.21 & 1.43 & 0.9 & 0.6 & 0.95 & 0.42 & 0.23 \\
\hline fpq & 0.48 & 6.11 & 1.05 & 1.41 & 1.22 & 0.39 & 0.94 & 0.35 \\
\hline glaq & 1.13 & 5.63 & 2.86 & 4.18 & 1.75 & 3.68 & 1.68 & 0.64 \\
\hline gpa & 0.60 & 5.81 & 1.69 & 3.01 & 1.7 & 1.61 & 0.63 & 1.37 \\
\hline ia & 0.12 & 3.77 & 0.62 & 0.8 & 0.47 & 1.26 & 1.23 & 0.38 \\
\hline $\mathrm{iaq}$ & 0.31 & 4.20 & 1.37 & 2.82 & 0.91 & 0.27 & 0.02 & 1.37 \\
\hline
\end{tabular}


TABle 4: Continued.

\begin{tabular}{|c|c|c|c|c|c|c|c|c|}
\hline Anomaly & $\begin{array}{c}(1) \\
\text { Mean (\%) }\end{array}$ & $\begin{array}{c}(2) \\
\text { Std. dev (\%) }\end{array}$ & $\begin{array}{c}(3) \\
\mathrm{t}-\mathrm{Raw} \\
\end{array}$ & $\begin{array}{c}(4) \\
\mathrm{t}-\mathrm{FF} 6\end{array}$ & $\begin{array}{c}\text { (5) } \\
\mathrm{t}-\mathrm{Q} 5 \\
\end{array}$ & $\begin{array}{c}(6) \\
\mathrm{t}-\mathrm{SY} 4 \\
\end{array}$ & $\begin{array}{c}(7) \\
\text { t-DHS3 }\end{array}$ & $\begin{array}{c}8) \\
\text { t-LSY4 }\end{array}$ \\
\hline ir & 0.23 & 5.94 & 0.69 & 0.23 & 3.23 & 2.14 & 2.49 & 1.89 \\
\hline isc & 0.31 & 3.68 & 1.38 & 1.06 & 2.07 & 1.02 & 0.95 & 1.91 \\
\hline isff & 0.25 & 3.43 & 1.06 & 1.13 & 1.49 & 1.56 & 0.92 & 2.56 \\
\hline isq & 0.27 & 3.60 & 1.2 & 1.43 & 2.18 & 2.24 & 0.91 & 2.51 \\
\hline iv & 0.74 & 6.22 & 2.01 & 3.36 & 3.28 & 5.17 & 2.1 & 1.56 \\
\hline ivc & 1.06 & 5.86 & 2.97 & 3.23 & 3.22 & 4.28 & 2.91 & 0.08 \\
\hline ivff & 1.19 & 5.70 & 3.17 & 3.7 & 4.05 & 4.47 & 2.94 & 0.56 \\
\hline ivg & 0.09 & 2.99 & 0.62 & 0.9 & 0.42 & 1.38 & 1.29 & 0.82 \\
\hline ivq & 1.15 & 5.79 & 2.92 & 3.22 & 3.59 & 4.14 & 2.7 & 0.61 \\
\hline $\mathrm{kzq}$ & 0.06 & 4.41 & 0.22 & 0.64 & 0.18 & 0.07 & 0.4 & 0.31 \\
\hline $\mathrm{mdr}$ & 0.73 & 5.51 & 2.32 & 2.83 & 2.24 & 2.93 & 2.08 & 1.44 \\
\hline me & 0.30 & 6.56 & 0.66 & 0.8 & 2.69 & 0.81 & 1.23 & 0.24 \\
\hline ndpq & 0.42 & 6.25 & 1.12 & 1.13 & 3.13 & 3.04 & 1.52 & 1.59 \\
\hline noa & 0.50 & 3.68 & 2.72 & 3.89 & 2.43 & 2.56 & 1.92 & 0.51 \\
\hline nopq & 0.40 & 4.93 & 1.36 & 1.87 & 2.4 & 4.41 & 2.03 & 0.01 \\
\hline nsi & 0.17 & 3.31 & 0.94 & 0.35 & 0.02 & 1.4 & 1.91 & 0.11 \\
\hline ocpq & 0.76 & 5.27 & 3.02 & 3.4 & 4.08 & 5.42 & 3.04 & 0.19 \\
\hline olaq & 0.75 & 6.27 & 1.71 & 3.15 & 0.5 & 3.33 & 0.59 & 0.19 \\
\hline oleq & 0.89 & 6.31 & 2.12 & 4.01 & 0.84 & 3.51 & 0.78 & 0.13 \\
\hline olq & 0.32 & 3.64 & 1.38 & 1.35 & 0.83 & 0.85 & 1.21 & 0.2 \\
\hline opa & 0.11 & 5.84 & 0.23 & 0.26 & 0.62 & 0.75 & 0.74 & 0.29 \\
\hline ope & 0.25 & 6.00 & 0.61 & 0.86 & 1.3 & 1.81 & 0.43 & 1.13 \\
\hline opq & 0.36 & 5.64 & 1.16 & 1.31 & 2.53 & 4.06 & 1.66 & 0.24 \\
\hline oq & 0.68 & 4.73 & 1.99 & 4.49 & 2.67 & 2.69 & 1.2 & 1.28 \\
\hline pmq & 0.87 & 5.19 & 2.58 & 4.64 & 1.3 & 4.11 & 1.43 & 1.29 \\
\hline poa & 0.12 & 3.61 & 0.81 & 0.69 & 0.32 & 1.39 & 0 & 0.44 \\
\hline pps & 0.77 & 7.20 & 1.74 & 1.56 & 3.7 & 5.11 & 4.64 & 0.73 \\
\hline $\mathrm{Ra} 25$ & 0.66 & 4.19 & 2.69 & 3.03 & 2.7 & 2.9 & 2.58 & 2.77 \\
\hline $\mathrm{Rn} 25$ & 0.77 & 6.61 & 2.21 & 1.25 & 2.16 & 3.48 & 2.89 & 1.85 \\
\hline r11 & 0.68 & 6.64 & 1.39 & 1.41 & 1.08 & 0.28 & 0.97 & 0.88 \\
\hline rla & 0.68 & 4.64 & 2.19 & 2.81 & 1.19 & 1.19 & 1.38 & 1.11 \\
\hline $\mathrm{r} \ln$ & 0.07 & 6.76 & 0.14 & 1.17 & 2.25 & 1.28 & 2.21 & 0.96 \\
\hline r6 & 0.25 & 6.49 & 0.56 & 0.1 & 0.74 & 0.32 & 1.67 & 1.91 \\
\hline rev & 0.40 & 5.38 & 1.44 & 0.97 & 2.04 & 2.29 & 2.4 & 1.8 \\
\hline rnaq & 1.28 & 5.51 & 3.89 & 5.04 & 1.56 & 5.83 & 2.2 & 0.62 \\
\hline roa & 1.34 & 5.65 & 3.5 & 4.97 & 2.38 & 5.51 & 1.98 & 1.4 \\
\hline roe & 1.51 & 5.71 & 4.41 & 5.62 & 2.29 & 6.29 & 2.35 & 0.98 \\
\hline rs & 0.57 & 3.61 & 2.05 & 1.46 & 0.18 & 1.53 & 0.39 & 0.3 \\
\hline sgq & 0.96 & 3.70 & 4.28 & 5.2 & 1.74 & 3.26 & 2.64 & 1.33 \\
\hline size & 0.66 & 7.06 & 1.28 & 3.41 & 1.79 & 0.9 & 2.39 & 1.51 \\
\hline $\mathrm{spq}$ & 1.16 & 6.55 & 2.59 & 3.12 & 3.1 & 5.3 & 3.11 & 0.52 \\
\hline $\mathrm{sr}$ & 0.11 & 4.68 & 0.33 & 0.56 & 0.4 & 0.34 & 0.12 & 0.1 \\
\hline srev & 0.91 & 6.29 & 2.68 & 3.14 & 2.81 & 2.35 & 3.4 & 0.5 \\
\hline sue & 1.28 & 3.81 & 5.5 & 6.09 & 2.05 & 4.95 & 3.16 & 1.64 \\
\hline tail & 0.33 & 3.75 & 1.45 & 1.88 & 0.05 & 0.89 & 0.84 & 0.7 \\
\hline $\tan q$ & 0.23 & 3.89 & 1.01 & 1.91 & 0.72 & 0.41 & 0.39 & 0.3 \\
\hline tbiq & 0.30 & 3.14 & 1.28 & 1.56 & 1.54 & 2.04 & 1.21 & 1.1 \\
\hline tes & 1.00 & 3.54 & 4.77 & 6.03 & 2.27 & 4.07 & 2.73 & 1.7 \\
\hline ts & 0.64 & 3.90 & 3.2 & 2.32 & 2.07 & 2.45 & 3.23 & 0.74 \\
\hline tur & 0.61 & 6.88 & 1.64 & 3.9 & 3.6 & 5.04 & 1.49 & 1.52 \\
\hline tv & 0.80 & 6.41 & 2.06 & 2.52 & 2.15 & 3.08 & 1.54 & 0.33 \\
\hline wwq & 0.07 & 7.12 & 0.16 & 0.45 & 2.77 & 2.79 & 0.21 & 0.08 \\
\hline $\mathrm{zq}$ & 0.05 & 6.47 & 0.13 & 0.7 & 1.51 & 2.79 & 0.98 & 0.12 \\
\hline
\end{tabular}

where $\gamma_{0}$ is the zero-beta rate, $h_{t}$ is a $p \times 1$ vector of benchmark factors, $g_{t}$ is a $q \times 1$ vector of new factors needed to be tested, and $\lambda_{g}$ and $\lambda_{h}$ are so-called SDF loadings. Given a vector of test asset returns $r_{t}$, we may want to evaluate the explanatory power of $g_{t}$ while controlling for other benchmark factors $h_{t}$. According to definition of SDF, formula (2) can be expressed as the relationship between expected returns and covariances with factors $h_{t}$ and $g_{t}$ : 
TABLE 5: Comparison of models in explaining anomalies. This table reports some statistics derived from using various factor models to explain 104 anomalies. We display results of the Fama-French 6-factor model [10], the Hou-Xue-Zhang q5-factor model [2], the Stambaugh-Yuan 4-factor model [21], the Daniel-Hirshleifer-Sun 3-factor model [22], and the Liu-Stambaugh-Yuan 4-factor model [15], in columns "FF6," "Q5," "SY4," "DHS3," and "LSY4," respectively. Average alpha and Average $t$ are the absolute mean of alphas and corresponding $t$-statistics over 104 anomalies. $\Delta$ is the cross-sectional pricing error with respect to each model, which is computed as formula (1). GRS is the statistic of well-known GRS test proposed by Shanken et al. [24].

\begin{tabular}{lllcrc}
\hline & FF6 & Q5 & SY4 & DHS3 & LSY4 \\
\hline Average alpha (\%) & 0.55 & 0.46 & 0.62 & 0.52 & 0.31 \\
Average $t$ & 2.21 & 1.64 & 2.29 & 1.55 & 3.93 \\
$\Delta$ & 3.91 & 3.61 & 4.29 & 3.65 \\
GRS & 4.26 & 3.59 & 5.11 & 3.33 \\
\hline
\end{tabular}

TABLE 6: Spanning regression. This table reports results of regressing FF6 factors, q5 factors, SY4 factors, and DHS-3 factors on LSY4 factors. MKT, SMB, VMG, and PMO are market, size, value, and turnover factors in the Liu-Stambaugh-Yuan 4-factor model [15]. HML, RMW, $\mathrm{CMA}$, and UMD are value, profitability, investment, and momentum factors in the Fama-French 6-factor model [10]. $R_{\mathrm{me}}, R_{\mathrm{ia}}, R_{\mathrm{roe}}$, and $R_{\mathrm{eg}}$ are size, investment, profitability, and expected growth factor in the Hou-Xue-Zhang q5-factor model [2]. MGMT and PERF are two mispricing factors in the Stambaugh-Yuan 4-factor model [21]. PEAD and FIN are two long-short horizon factors in the Daniel-Hirshleifer-Sun 3-factor model [22]. For each factor, we report its coefficient estimate and corresponding $t$-statistic (given in parentheses). $R^{2}$ is adjusted $R$-squared of each regression, and D-W Stat. is corresponding Durbin-Watson statistic of each regression.

\begin{tabular}{|c|c|c|c|c|c|c|c|}
\hline & Alpha & Mktrf & SMB & VMG & $\mathrm{PMO}$ & $R^{2}$ & D-W stat. \\
\hline HML & $\begin{array}{c}0.39 \\
-1.48\end{array}$ & $\begin{array}{c}0.06^{* *} \\
-2\end{array}$ & $\begin{array}{c}-0.27^{* * *} \\
(-3.79)\end{array}$ & $\begin{array}{c}0.29^{* * *} \\
-3.25\end{array}$ & $\begin{array}{c}-0.28^{* * *} \\
(-3.98)\end{array}$ & 0.26 & 2 \\
\hline RMW & $\begin{array}{c}-0.14 \\
(-0.85)\end{array}$ & $\begin{array}{c}-0.05^{* *} \\
(-2.52)\end{array}$ & $\begin{array}{r}-0.27^{* * *} \\
(-5.74)\end{array}$ & $\begin{array}{c}0.43^{* * *} \\
-7.55\end{array}$ & $\begin{array}{c}0.10^{* *} \\
-2.2\end{array}$ & 0.55 & 1.85 \\
\hline CMA & $\begin{array}{c}-0.03 \\
(-0.16)\end{array}$ & $\begin{array}{c}-0.03 \\
(-1.30)\end{array}$ & $\begin{array}{c}0.14^{* * *} \\
-2.85\end{array}$ & $\begin{array}{c}-0.01 \\
(-0.07)\end{array}$ & $\begin{array}{c}-0.16^{* * *} \\
(-3.26)\end{array}$ & 0.07 & 1.85 \\
\hline UMD & $\begin{array}{c}0.28 \\
-0.99\end{array}$ & $\begin{array}{c}-0.04 \\
(-1.17)\end{array}$ & $\begin{array}{c}-0.33^{* * *} \\
(-4.22)\end{array}$ & $\begin{array}{c}0.06 \\
-0.58\end{array}$ & $\begin{array}{c}0.09 \\
-1.23\end{array}$ & 0.14 & 1.93 \\
\hline$R_{\mathrm{me}}$ & $\begin{array}{c}0.19^{*} \\
-1.9\end{array}$ & $\begin{array}{c}0 \\
(-0.05)\end{array}$ & $\begin{array}{l}0.75^{* * *} \\
-27.25\end{array}$ & $\begin{array}{l}-0.06^{*} \\
(-1.85)\end{array}$ & $\begin{array}{c}0.04 \\
-1.37\end{array}$ & 0.85 & 2.11 \\
\hline$R_{\mathrm{ia}}$ & $\begin{array}{c}-0.06 \\
(-0.41)\end{array}$ & $\begin{array}{l}-0.02 \\
(-1.13)\end{array}$ & $\begin{array}{l}0.10^{* *} \\
-2.24\end{array}$ & $\begin{array}{c}0.13^{* *} \\
-2.48\end{array}$ & $\begin{array}{l}-0.08^{*} \\
(-1.79)\end{array}$ & 0.03 & 2.13 \\
\hline$R_{\text {roe }}$ & $\begin{array}{c}0.07 \\
-0.48\end{array}$ & $\begin{array}{c}-0.02 \\
(-1.43)\end{array}$ & $\begin{array}{c}-0.05 \\
(-1.24)\end{array}$ & $\begin{array}{c}0.74^{* * *} \\
-14.87\end{array}$ & $\begin{array}{l}0.07^{*} \\
-1.88\end{array}$ & 0.66 & $1.74^{* *}$ \\
\hline$R_{\mathrm{eg}}$ & $\begin{array}{c}0.1 \\
-0.42\end{array}$ & $\begin{array}{c}0.03 \\
-1.27\end{array}$ & $\begin{array}{c}-0.16^{* *} \\
(-2.42)\end{array}$ & $\begin{array}{c}0.25^{* * *} \\
-3.11\end{array}$ & $\begin{array}{c}-0.18^{* * *} \\
(-2.93)\end{array}$ & 0.17 & 1.88 \\
\hline MGMT & $\begin{array}{c}-0.11 \\
(-0.47)\end{array}$ & $\begin{array}{c}-0.02 \\
(-0.85)\end{array}$ & $\begin{array}{l}0.16^{* *} \\
-2.52\end{array}$ & $\begin{array}{c}0.03 \\
-0.43\end{array}$ & $\begin{array}{c}-0.05 \\
(-0.78)\end{array}$ & 0.02 & 2.08 \\
\hline PERF & $\begin{array}{c}-0.03 \\
(-0.11)\end{array}$ & $\begin{array}{c}-0.09^{* *} \\
(-2.51)\end{array}$ & $\begin{array}{l}-0.05 \\
(-0.59)\end{array}$ & $\begin{array}{c}0.52^{* * *} \\
-5.1\end{array}$ & $\begin{array}{l}0.18^{* *} \\
-2.32\end{array}$ & 0.25 & 1.98 \\
\hline PEAD & $\begin{array}{c}0.72^{* * *} \\
-3.35\end{array}$ & $\begin{array}{c}-0.05^{* *} \\
(-2.09)\end{array}$ & $\begin{array}{c}0.03 \\
(-0.45)\end{array}$ & $\begin{array}{c}0.28^{* * *} \\
-3.86\end{array}$ & $\begin{array}{c}0 \\
(-0.04)\end{array}$ & 0.14 & 1.96 \\
\hline FIN & $\begin{array}{c}0.08 \\
-0.51\end{array}$ & $\begin{array}{c}0.02 \\
-1.14\end{array}$ & $\begin{array}{c}-0.03 \\
(-0.66)\end{array}$ & $\begin{array}{c}0.08 \\
-1.35\end{array}$ & $\begin{array}{c}-0.05 \\
(-1.20)\end{array}$ & 0.02 & 1.95 \\
\hline
\end{tabular}

$$
E\left(r_{t}\right)=\iota_{n} \gamma_{0}+C_{v} \lambda_{v}=\iota_{n} \gamma_{0}+C_{g} \lambda_{g}+C_{h} \lambda_{h}
$$

where $E\left(r_{t}\right)$ is a $n \times 1$ vector of expected returns, $\iota_{n}$ is a $n \times 1$ vector of ones, $C_{g}$ is the covariance matrix of $r_{t}$ and $g_{t}, C_{h}$ is the covariance matrix of $r_{t}$ and $h_{t}$. Intuitively, SDF loadings $\lambda_{g}$ and $\lambda_{h}$ measure how expected return is correlated to its covariances with corresponding factors. However, since we mainly focus on the significance of $\lambda_{g}$, considering dependence between $h_{t}$ and $g_{t}$, it is worthwhile to project $C_{g}$ on $C_{h}$ :

$$
C_{g}=\iota_{n} \xi+C_{h} \dot{\chi}+C_{e}
$$

where $\xi$ and $\chi$ are coefficient matrices and $C_{e}$ is the residual matrix.
Because there are a number of pricing factors in the real world (Fama-French factors, Hou-Xue-Zhang q-factors, etc.), we need to determine the components of $h_{t}$ before we test $g_{t}$. It requires us to select factors with the most explanatory power to serve as the benchmark. Least Absolute Shrinkage Selection Operator (LASSO) regression is one of approaches to help us reduce the number of benchmark factors. LASSO is a modification of the RIDGE regression method where the constraint in the Lagrangian is the absolute values of the parameters and where the Lagrange multiplier governs the shrinkage Eric Ghysels [28]. Specifically, we run a cross-sectional LASSO regression of mean returns on the covariance between returns and all benchmark factors: 


$$
\min _{\gamma, \lambda}\left\{n^{-1}\left(\bar{r}-\iota_{n} \gamma-\widehat{C_{h}} \lambda\right)^{2}+\tau_{0} n^{-1}|\lambda|_{1}\right\},
$$

where $\bar{r}$ is the time series mean of all test asset returns, $\widehat{C_{h}}$ is the covariance matrix of $\bar{r}$ and demeaned $h_{t}$, and $\tau_{0}$ is the LASSO penalty parameter. We usually rely on cross validation to choose $\tau_{0}$ and solve the Lasso coefficients $\lambda$ with least angle algorithm [29] or coordinate descent algorithm [30]. LASSO regression will shrink some $\lambda$ to zero and generate a sparse function specification. We denote the indices of remaining benchmark factors as set $\left\{\hat{I}_{1}\right\}$.

However, in finite sample, traditional LASSO regression does not have the so-called "oracle property," that is, we cannot select the true model with the probability of one. It indicates the result given by previous LASSO regression suffers from severe omitted variable bias, which means our inference about loadings $\gamma$ may be erroneous. Thus, performing a single LASSO step is not enough to make sure we can control all useful benchmark factors for testing $g_{t}$. We need to conduct another LASSO regression to search for factors which are omitted in the first step but still play a role in explaining test asset returns:

$$
\min _{\xi_{j}, \chi_{j}}\left\{n^{-1}\left(\widehat{C_{g_{i}},}-\iota_{n} \xi_{j}-\widehat{C_{h}} \chi_{j,},\right)^{2}+\tau_{j} n^{-1}\left|\chi_{j,},\right|_{1}\right\},
$$

where $\widehat{C_{g}}$ is the covariance matrix of $\bar{r}$ and demeaned $g_{t}$. Intuitively, for each new factor $g_{j}$, we identify the corresponding benchmark factors whose covariance with mean returns are closest to covariance between mean returns and factor $g_{j}$. Denote the union of all indices of selected benchmark factors as set $\widehat{I}_{2}=\cup_{j=1}^{d} \widehat{I_{2, j}}$.

So far, we have performed two rounds of LASSO regressions to select sufficient benchmark factors. Now, we can evaluate the marginal importance of new factors $g_{t}$ with following cross-sectional regression. We are concerned about SDF loadings $\lambda_{g}$, which tell us whether the corresponding factors $g_{t}$ are significant to price test asset returns:

$$
\left(\widehat{\gamma_{0}}, \widehat{\lambda_{g}}, \widehat{\lambda_{h}}\right)=\underset{\gamma_{0}, \lambda_{g}, \lambda_{h}}{\arg \min }\left\{\left(\bar{r}-\iota_{n} \gamma_{0}-\widehat{C_{g}} \lambda_{g}-\widehat{C_{h}} \lambda_{h}\right)^{2}: \lambda_{h, j}=0, \forall j \notin \widehat{I}=\widehat{I_{1}} \cup \widehat{I_{2}}\right\} .
$$

4.2. Factors and Test Portfolios. We construct our factor library based on previous discussion. Note that the aim of this section is to explore explanatory power of some new factors beyond a series of benchmark factors. Thus, the vector $h_{t}$ includes all pricing factors appearing in Table 2 , which come from mainstream factor models in latest literature. In addition, we also add another two factors. The first one is QMJ, a Quality-Minus-Junk factor proposed by Asness et al. [31]. The other is a liquidity factor AMI, which is constructed by Amihud's measure. Both factors are confirmed to have significant return spreads in A-share market, see details in Kang and Zhang [32] and Hu and Gu [33]. Our main empirical results are derived from these 18 benchmark factors in total. Someone may argue the volume of our factor library is too small to evaluate the contributions of new latent factors, especially compared to related literature in the US market. We respond to this doubt from two aspects. First, unlike the US market, there is no clear timeline of published date for newly discovered factors in China. Using the A-share market data, related studies mainly focus on testing the significance of factors discovered in developed countries. The purpose of our paper is to investigate whether we can add new factors into the baseline LSY4 model; hence, it is natural to denote current pricing factors as benchmark factors. Second, as a robustness check, we also expand the factor library to accommodate all the other anomalies in Table 1 except for anomalies we are going to test. However, we find our empirical result changes a little, indicating current pricing factors are powerful enough to subsume the main part of cross-sectional test asset returns.

For vector of new factors $g_{t}$, we firstly consider significant anomalies unexplained by the LSY4 model. Table 4 shows only 6 anomalies can yield significant LSY4 alphas.
Among them, cumulative abnormal returns around earnings' announcement dates (abr), Dimson beta (betad), and one measure of seasonality (ra25) have significant return spreads. We suppose these three factors are proper candidates of latent new factors. Besides, we link to the work of Qiao [8], who replicates 231 anomalies in the A-share market. We test significant anomalies found in this paper, including quarterly assets-to-market (amq), changes in return on assets (droa), changes in return on equity (droe), dollar trading volume (dtv), idiosyncratic volatility per the FF3 model (ivff), long-term reversal (lrev), price momentum with prior 24 month returns (m24), maximum daily return (mdr), R\&D expense to market equity ( $\mathbf{r d m}$ ), quarterly sales growth (sgq), quarterly sales-to-price ratio (spq), short-term reversal (srev), total volatility (tv), variation of share dollar trading volume (vdtv), and variation of share turnover (vturn). Note that some of these anomalies have been investigated by us in the previous section. Although they may generate insignificant return spreads according to Table 4 , we still add them into the set of $g_{t}$ since it will contribute to literature in this field. Certainly, we reconstruct these anomalies following the standard procedure of Fama and French [18] in order to compare with other factors. For each anomaly, we split stocks into 3 portfolios according to 30 and 70 percentiles of corresponding characteristic. Note that high rankings are associated with higher future average returns. Meanwhile, we also split stocks into two groups according to the median size. Factor returns are spreads between the average of two high-characteristic portfolios and the average of two lowcharacteristic portfolios.

We use 650 portfolios as test assets based on our factor library. Following the procedure of Fama and French [18], 
stocks are independently sorted into $5 \times 5$ portfolios by the market value and one firm characteristic. In order to avoid imposing a specific factor structure on our test portfolios, we choose as many characteristics as possible, all of which are used to construct factors in $h_{t}$ and $g_{t}$. The sorting characteristics include cumulative abnormal returns around earnings announcement dates, turnover, Amihud's liquidity measure, quarterly assets-to-market, Dimson beta, book-tomarket ratio, changes in return on assets, changes in return on equity, dollar trading volume, expected investment growth, earnings-to-price ratio, investment growth, idiosyncratic volatility per the FF3 model, long-term reversal, price momentum with prior 24 month returns, maximum daily return, 11-month momentum, seasonality, R\&D expense to market equity, return on equity, quarterly sales growth, quarterly sales-to-price ratio, short-term reversal, total volatility, variation of share dollar trading volume, and variation of share turnover. In robustness check, we also form another $1563 \times 2$ portfolios.

4.3. Empirical Results. Now, we apply the double-selection LASSO approach to A-share market. We start by reporting summary statistics of factors in $h_{t}$ and $g_{t}$, which are not introduced during previous discussion. Table 7 displays means, $t$-statistics, annualized Sharpe ratios, skewness, kurtosis, and Jarque-Bera statistics of totally 20 factors. To some extent, we find all these factors have significant return spreads except for long-term reversal (lrev) and price momentum with prior 24 month returns (m24). It is a little inconsistent with findings of Qiao [8]. Compared to their work, we exclude the smallest $30 \%$ stocks while constructing factors. On the contrary, Table 7 indicates our selection for tested factors is quite reasonable, since most of them yield extremely high $t$-statistics. Similar to discovered pricing factors we discussed before, these alternative factors also have leptokurtosis and fat tails.

We are interested in whether those factors with significant risk premia contribute to explaining cross-sectional returns. As emphasized by Feng et al. [11] and Cochrane [26], the key to answering this question is to compare factors' SDF loadings. A positive SDF loading indicates the high value of this factor captures good states of the world, and vice versa. Columns 1-2 of Table 8 report our SDF loading estimates as well as $t$-statistics using double LASSO approach. The two steps select totally 4 benchmark factors, including expected growth $\left(R_{\text {eg }}\right)$, quality-minus-junk (QMJ), liquidity (AMI), and market excess return (MKT), where the first three factors are derived from the first step and the last one is derived from the second step. One may argue that why these four factors can serve as the benchmark instead of LSY4 factors. It needs to be emphasized that the members of selected benchmark factors highly depend on test assets. As for returns of our 650 test portfolios, the factors above show greater explanative ability than LSY4 factors. This inference is obtained from Table 8 . In columns 1-2, we find 8 out of 18 tested factors have significant SDF loadings with the significance level of 0.05 , most of which are categorized into trading frictions. In comparison, when we use LSY4 factors as controls, as shown in columns 3-4, the number of significant tested factors rises to 12 . Since we do not select benchmark factors optimally, the estimate of SDF loadings suffers from omitted variable bias and is possibly imprecise. Furthermore, in columns 5-6, we add all 18 benchmark factors simultaneously into the regression to estimate SDF loadings. The result is similar to using LSY4 factors, with 11 significant factors. Selecting proper benchmark factors is important to evaluate the contributions of new factors. In fact, as pointed out by Feng et al. [11], controlling all available factors is an unbiased but inefficient approach, and the inefficiency becomes especially severe when the dimension of factor space is large. We will show this in Table 9.

We next show robustness of our results since double LASSO approach relies on two inputs: returns of test portfolios and the set of benchmark factors. In Table 10, we re-estimate SDF loadings by changing test portfolios and expanding the dimension of $h_{t}$. Firstly, we replace 650 test portfolios with fewer 156 portfolios. Then, we test extra benchmark factors which are anomalies presented in Table 4 but excluding the ones we need to test. Certainly, we follow the standard procedures to convert anomaly returns to factor returns, that is, we use spreads between two bivariate portfolios sorted by size and a specific characteristic instead of long-short decile spreads. In this way, we obtain another 81 benchmark factors and the total number increases to 99 . Intuitively, we want to explore whether these tested factors can distinctively explain cross-sectional returns beyond the rest of characteristic-based anomalies. For convenience, Table 10 reports our baseline results in the left. Generally speaking, we find the results derived from 99 benchmark factors are similar to using only 18 benchmark factors. That indicates the original 18 factors can dominate the others when explaining variation of asset returns. On the contrary, it shows SDF loadings are less significant when we use only 156 portfolios. As we have mentioned before, the selection of test assets will influence the SDF loading estimates. However, we still find some tested factors kept significant over different cases, including cumulative abnormal returns around earnings' announcement dates (abr), Dimson beta (betad), changes in return on assets (droa), changes in return on equity (droe), and idiosyncratic volatility per FF3 model (ivff). We suppose these factors indeed contribute to explaining cross-sectional returns.

Finally, we investigate whether aforementioned factors can augment the performance of the LSY4 model. Besides the five newly found factors, we also consider quality-minus-junk (QMJ) and liquidity (AMI), both of which are selected from the first step of LASSO. In practice, we augment the LSY4 model to a 5 -factor model by adding new factors into the original model one by one. Similar to the previous section, as for a new factor model, we mainly focus on its ability to explain anomalies and other pricing factors. Table 11 shows the results. The first two rows report the GRS statistics and average $t$-statistics in explaining 104 anomalies. The last two rows are derived from simplified spanning regressions that only report alphas of two pricing factors, $R_{\mathrm{me}}$ and PEAD. Note that these two factors still have significant alphas even if they are controlled by LSY4 factors. By comparison, we find 
TABLE 7: Summary statistics of other factors. This table reports means, $t$-statistics, annualized Sharpe ratios, skewness, kurtosis, and Jarque-Bera statistics of factors which do not appear in previous models but are used in our double-selection LASSO approach. The sample period is from July 2000 to December 2019. AMI and QMJ denote the liquidity factor and Quality-Minus-Junk factor, respectively. Other factors are based on anomalies in Qiao [8] but reconstructed using bivariate $2 \times 3$ portfolios following Fama and French [18].

\begin{tabular}{|c|c|c|c|c|c|}
\hline & (1) & (2) & (3) & (4) & (5) \\
\hline Factor & AMI & QMJ & abr & amq & betad \\
\hline Mean (\%) & 1.05 & 0.83 & 0.44 & 0.50 & 0.85 \\
\hline$t$-value & 4.81 & 3.56 & 2.94 & 1.72 & 3.73 \\
\hline Sharpe ratio & 1.09 & 0.81 & 0.67 & 0.39 & 0.84 \\
\hline Skewness & 0.35 & 0.22 & -0.07 & 0.01 & 0.88 \\
\hline Kurtusis & 6.69 & 4.41 & 4.89 & 7.10 & 5.03 \\
\hline \multirow[t]{2}{*}{ J-B stat. } & 137.30 & 21.30 & 34.86 & 164.12 & 70.80 \\
\hline & (6) & (7) & (8) & (9) & (10) \\
\hline Factor & droa & droe & dtv & ivff & lrev \\
\hline Mean (\%) & 0.85 & 0.88 & 0.75 & 1.04 & 0.16 \\
\hline$t$-value & 7.42 & 7.15 & 3.82 & 5.30 & 0.72 \\
\hline Sharpe ratio & 1.68 & 1.62 & 0.87 & 1.20 & 0.16 \\
\hline Skewness & 0.19 & 0.16 & 0.06 & 0.12 & 0.34 \\
\hline Kurtusis & 4.37 & 4.63 & 4.73 & 4.94 & 6.11 \\
\hline \multirow[t]{2}{*}{ J-B stat. } & 19.81 & 26.93 & 29.45 & 37.15 & 98.84 \\
\hline & (11) & (12) & (13) & (14) & (15) \\
\hline Factor & $\mathrm{m} 24$ & mdr & ra25 & rdm & sgq \\
\hline Mean (\%) & 0.08 & 0.66 & 0.35 & 0.60 & 0.88 \\
\hline$t$-value & 0.54 & 3.38 & 2.26 & 3.54 & 5.91 \\
\hline Sharpe ratio & 0.12 & 0.77 & 0.51 & 0.80 & 1.34 \\
\hline Skewness & 0.04 & -0.13 & 0.71 & 0.19 & 0.27 \\
\hline Kurtusis & 4.14 & 3.81 & 5.20 & 7.57 & 5.80 \\
\hline \multirow[t]{2}{*}{ J-B stat. } & 12.78 & 7.02 & 67.01 & 205.41 & 79.24 \\
\hline & (16) & (17) & (18) & (19) & (20) \\
\hline Factor & spq & Srev & tv & vdtv & vturn \\
\hline Mean (\%) & 0.58 & 0.79 & 0.48 & 0.98 & 0.91 \\
\hline$t$-value & 2.51 & 3.77 & 1.93 & 4.91 & 3.84 \\
\hline Sharpe ratio & 0.57 & 0.85 & 0.44 & 1.11 & 0.87 \\
\hline Skewness & 0.12 & 0.51 & -0.45 & 0.51 & -0.52 \\
\hline Kurtusis & 7.65 & 4.89 & 4.12 & 6.23 & 6.71 \\
\hline J-B stat. & 211.40 & 44.67 & 20.15 & 112.10 & 144.83 \\
\hline
\end{tabular}

TABLE 8: Testing SDF loadings of $g_{t}$. This table reports SDF loading estimates of 18 tested factors with significant risk premia in the A-share market. We use $6505 \times 5$ bivariate sorted portfolios as test assets. Benchmark factors include all factors appearing in Table 3 as well as the liquidity factor AMI and Quality-Minus-Junk (QMJ) factor. The sample period is from July 2000 to December 2019. The first column uses double-selection LASSO approach to determine controlling factors. The second column only uses factors of Liu-Stambaugh-Yuan 4-factor model [15] as controls. The third column uses all 18 benchmark factors as controls.

(1)

Double Lasso
(2)

ChF4
(3)

All

\begin{tabular}{|c|c|c|c|c|c|c|}
\hline & Coef & $t$-value & Coef & $t$-value & Coef & $t$-value \\
\hline abr & 8.77 & $3.29^{* * *}$ & 6.89 & $2.69^{* * *}$ & -0.02 & $-0.01^{* *}$ \\
\hline $\mathrm{amq}$ & -3.02 & -0.89 & -2.88 & -0.96 & 12.74 & $2.22^{* *}$ \\
\hline betad & 8.97 & $3.86^{* * *}$ & 5.51 & $2.31^{* *}$ & 7.03 & $2.84^{* * *}$ \\
\hline droa & 52.64 & $3.81^{* * *}$ & 39.88 & $3.19^{* * *}$ & 41.02 & $2.71^{* * *}$ \\
\hline droe & -21.84 & $-1.77^{*}$ & -5.85 & -0.51 & -9.19 & -0.71 \\
\hline dtv & 16.75 & $2.59^{* * *}$ & 33.54 & $5.29^{* * *}$ & 33.64 & $4.17^{* * *}$ \\
\hline ivff & 27.06 & $7.35^{* * *}$ & 23.35 & $6.79^{* * *}$ & 15.74 & $3.86^{* * *}$ \\
\hline lrev & -2.82 & -1.26 & -4.5 & $-2.33^{* *}$ & 0.29 & 0.1 \\
\hline $\mathrm{m} 24$ & 0.58 & 0.2 & 7.27 & $2.72^{* * *}$ & 6.09 & $1.68^{*}$ \\
\hline $\mathrm{mdr}$ & -13.95 & $-3.36^{* * *}$ & -8.32 & $-2.09^{* *}$ & 3.3 & 0.62 \\
\hline ra25 & -4.53 & $-1.93^{*}$ & -6.49 & $-2.83^{* * *}$ & 0.66 & 0.25 \\
\hline $\mathrm{rdm}$ & 3.42 & 0.77 & 6.75 & 1.57 & 12.63 & $2.46^{* *}$ \\
\hline sgq & -1.66 & -0.49 & -14.71 & $-4.31^{* * *}$ & -13.99 & $-3.62^{* * *}$ \\
\hline
\end{tabular}


TABLE 8: Continued.

\begin{tabular}{|c|c|c|c|c|c|c|}
\hline & \multicolumn{2}{|c|}{ (1) } & \multicolumn{2}{|c|}{ (2) } & \multicolumn{2}{|c|}{ (3) } \\
\hline & \multicolumn{2}{|c|}{ Double Lasso } & \multicolumn{2}{|c|}{$\mathrm{ChF} 4$} & \multicolumn{2}{|c|}{ All } \\
\hline & Coef & $t$-value & Coef & $t$-value & Coef & $t$-value \\
\hline $\mathrm{spq}$ & 6.13 & 1.21 & -2.43 & -0.44 & -6.55 & -1.06 \\
\hline srev & 3.8 & $1.97^{* *}$ & 1.74 & 0.91 & -0.2 & -0.08 \\
\hline tv & -5.32 & -1.13 & -7.69 & -1.64 & -10.75 & $-1.91^{* *}$ \\
\hline vdtv & -16.99 & $-2.32^{* *}$ & -28.3 & $-3.83^{* * *}$ & -38.21 & $-4.24^{* * *}$ \\
\hline vturn & -1.19 & -0.48 & 6.68 & $2.95^{* * *}$ & 10.99 & $3.68^{* * *}$ \\
\hline
\end{tabular}

TABLE 9: Testing SDF loadings of $g_{t}$ controlling all benchmark factors. This table reports testing results of SDF loading estimates controlling all 99 benchmark factors simultaneously. The sample period is from July 2000 to December 2019. In column 1, we use previous $6505 \times 5$ bivariate sorted portfolios as test assets, while, in column 2, we use $1562 \times 3$ bivariate sorted portfolios.

\begin{tabular}{|c|c|c|c|}
\hline & & & \\
\hline & & & \\
\hline Coef & $t$-value & Coef & $t$-value \\
\hline 16.53 & $2.372^{* *}$ & 29.9 & 1.23 \\
\hline-13.71 & -0.879 & 93.76 & $1.87^{*}$ \\
\hline 17.46 & $3.294^{* * *}$ & 61.15 & $3.52^{* * *}$ \\
\hline 52.44 & 1.774 & 161.05 & 1.43 \\
\hline 3.08 & 0.127 & -30.72 & -0.342 \\
\hline-22.83 & -1.431 & -42.48 & -0.836 \\
\hline-13.15 & -0.854 & -73.88 & -1.297 \\
\hline-6.14 & -0.825 & -12.64 & -0.441 \\
\hline 14.89 & 1.925 & -28.3 & -0.957 \\
\hline 11.13 & 1.162 & -1.93 & -0.048 \\
\hline 2.78 & 0.413 & 34.41 & 1.358 \\
\hline 13.48 & 1.211 & 9.68 & 0.276 \\
\hline 2.18 & 0.224 & 89.84 & $2.21^{* *}$ \\
\hline-8.73 & -0.566 & 35.83 & 0.539 \\
\hline-6.46 & -1.269 & -8.55 & -0.415 \\
\hline-8.9 & -0.832 & 40.41 & 1.092 \\
\hline-6.43 & -0.395 & -12.07 & -0.158 \\
\hline 16.25 & 1.215 & -51.08 & -0.77 \\
\hline
\end{tabular}

TABLE 10: Robustness for testing SDF loadings of $g_{t}$. This table reports robustness results of SDF loading estimates using double-selection LASSO approach. The sample period is from July 2000 to December 2019. In columns 1 and 2, we use previous $6505 \times 5$ bivariate sorted portfolios as test assets, while, in columns 3 and 4 , we use $1562 \times 3$ bivariate sorted portfolios. Columns 1 and 3 select controls from factors appearing in Table 3 as well as the liquidity factor AMI and Quality-Minus-Junk (QMJ) factor, while columns 2 and 4 select controls from an expanding set including totally 99 benchmark factors.

$$
5 \times 5 \text { portfolios }
$$

(1)
(2)

9 factors

$$
2 \times 3 \text { portfolios }
$$

\begin{tabular}{|c|c|c|c|c|c|c|c|c|}
\hline & Coef & $t$-value & Coef & $t$-value & Coef & $t$-value & Coef & $t$-value \\
\hline Abr & 8.77 & $3.29^{* * *}$ & 6.47 & $2.28^{* *}$ & 16.1 & $3.70^{* * *}$ & 15.44 & $3.35^{* * *}$ \\
\hline Amq & -3.02 & -0.89 & -13.89 & $-2.66^{* *}$ & -8.07 & -1.5 & -10.39 & -1.07 \\
\hline Betad & 8.97 & $3.86^{* * *}$ & 10.03 & $4.01^{* * *}$ & 7.38 & $1.89^{*}$ & 5.1 & 1.17 \\
\hline Droa & 52.64 & $3.81^{* * *}$ & 60.94 & $4.58^{* * *}$ & 73.33 & $2.30^{* *}$ & 78.06 & $2.43^{* *}$ \\
\hline Droe & -21.84 & $-1.77^{*}$ & -26.2 & $-2.18^{* *}$ & -48.56 & $-1.65^{*}$ & -50.97 & $-1.72^{*}$ \\
\hline dtv & 16.75 & $2.59^{* * *}$ & 7.38 & 1.17 & -5.73 & -0.37 & -6.99 & -0.44 \\
\hline ivff & 27.06 & $7.35^{* * *}$ & 20.16 & $2.46^{* *}$ & 43.09 & $5.85^{* * *}$ & 19.7 & 0.95 \\
\hline lrev & -2.82 & -1.26 & -2.3 & -1.12 & -1.87 & -0.49 & -2.49 & -0.64 \\
\hline $\mathrm{m} 24$ & 0.58 & 0.2 & 3.88 & 1.35 & 10.83 & $2.07^{* *}$ & 10.91 & $2.04^{* *}$ \\
\hline
\end{tabular}

(4) 
TABle 10: Continued.

\begin{tabular}{|c|c|c|c|c|c|c|c|c|}
\hline & \multicolumn{4}{|c|}{$5 \times 5$ portfolios } & \multicolumn{4}{|c|}{$2 \times 3$ portfolios } \\
\hline & \multicolumn{2}{|c|}{ (1) } & \multicolumn{2}{|c|}{ (2) } & \multicolumn{2}{|c|}{ (3) } & \multicolumn{2}{|c|}{$(4)$} \\
\hline & \multicolumn{2}{|c|}{18 factors } & \multicolumn{2}{|c|}{99 factors } & \multicolumn{2}{|c|}{18 factors } & \multicolumn{2}{|c|}{99 factors } \\
\hline & Coef & $t$-value & Coef & $t$-value & Coef & $t$-value & Coef & $t$-value \\
\hline$\overline{\mathrm{mdr}}$ & -13.95 & $-3.36^{* * *}$ & -14.39 & $-3.39^{* * *}$ & -12.15 & -1.42 & -7.88 & -0.85 \\
\hline ra25 & -4.53 & $-1.93^{* *}$ & -7.91 & $-3.05^{* * *}$ & 4 & 0.92 & 3.68 & 0.75 \\
\hline $\mathrm{rdm}$ & 3.42 & 0.77 & 6.79 & 1.45 & -4.41 & -0.48 & -1.15 & -0.11 \\
\hline sgq & -1.66 & -0.49 & 0.31 & 0.09 & 9.48 & 1.46 & 10.24 & 1.57 \\
\hline spq & 6.13 & 1.21 & 9.11 & $1.66^{*}$ & 19.32 & $1.82^{*}$ & 13.77 & 1.19 \\
\hline srev & 3.8 & $1.97^{* *}$ & 2.97 & 1.52 & -2.12 & -0.54 & -3.57 & -0.86 \\
\hline tv & -5.32 & -1.13 & -0.73 & -0.14 & -15.54 & -1.63 & -22.45 & $-2.00^{* *}$ \\
\hline vdtv & -16.99 & $-2.32^{* *}$ & -4.66 & -0.63 & 10.26 & 0.6 & 7.32 & 0.38 \\
\hline vturn & -1.19 & -0.48 & -3.59 & -1.28 & -12.27 & $-2.38^{* *}$ & -9.95 & $-1.70^{* *}$ \\
\hline
\end{tabular}

TABLE 11: Comparision of new factors in explaining anomalies. This table reports results of explaining 104 anomalies using augmented Liu-Stambaugh-Yuan 4-factor models [15]. The first column corresponds to our baseline result. We add seven new factors into the Liu-Stambaugh-Yuan 4-factor model one by one, including Quality-Minus-Junk, liquidity, cumulative abnormal returns around earnings' announcement dates, Dimson beta, 4-quarter change in return on assets, and 4-quarter change in return on equity and idiosyncratic volatility per the FF3 model, in columns labeled "QMJ," “AMI," “abr," "betad," "droa," "droe," and "ivff.” The first two rows display GRS statistics proposed by Shanken et al. [24] and absolute average $t$-statistics of alphas over 104 anomalies. The last two rows display alpha estimates and corresponding t-statistics (in parentheses) of regressing PEAD and $R_{\mathrm{me}}$ on augmented models. PEAD is the short horizon factor in the Daniel-Hirshleifer-Sun 3-factor model [22]. $R_{\mathrm{me}}$ is the size factor in the Hou-Xue-Zhang q5-factor model [2].

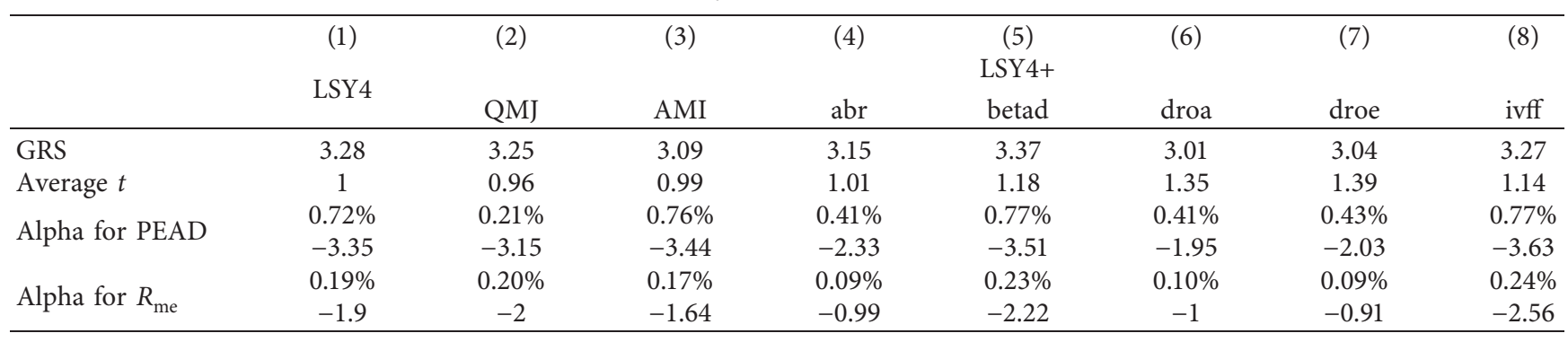

abr, droa, and droe can improve the performance of the LSY4 model. All of the three factors can reduce the value of GRS statistic as well as alphas of $R_{\mathrm{me}}$ and PEAD. However, the improvement is limited. None of them can totally explain all anomalies and eliminate the significance of the factor PEAD. Thus, we suppose relying on current factor zoo is hard to enhance the pricing power of the LSY4 model. New characteristics beyond our data library are needed. We hope our paper can inspire future research in this field.

\section{Conclusion}

The "factor zoo" problem is a hot issue in empirical asset pricing. Given the short history and incomplete trade regulations of the Chinese A-share market, few studies focus on addressing this issue in China. Our study aims to fill this gap by testing the performance of pricing factors emerging in recent studies. Using A-share market data, we replicate a generation of pricing factors and construct a characteristic library. By explaining 104 anomalies and performing spanning regressions, we verify the Liu-Stambaugh-Yuan four-factor model dominates other counterparts in the A-share market, including the Fama-French six-factor factor model, the Hou-Xue-Zhang q5-factor model, the
Stambaugh-Yuan four-factor model, and the Daniel-Hirshleifer-Sun three-factor model. Next, to explore whether there exist latent factors which have explanatory power beyond current factor models, we use a double-selection LASSO approach to estimate SDF loadings. Although we find some anomalies play a significant role in pricing cross-sectional returns, once we add them into the LiuStambaugh-Yuan four-factor model, the improvement is limited. We suppose future research should not be restricted in the current factor zoo when coming up with new factor models.

\section{Data Availability}

The trading data and financial data were collected from China Stock Market \& Accounting Research Database (https://www.gtarsc.com/) and independently construct factors as well as anomalies in the A-share market. The data used to support the findings of the study are available from the corresponding author upon request.

\section{Conflicts of Interest}

The authors declare that they have no conflicts of interest. 


\section{Supplementary Materials}

The details to construct factors are provided in the Supplementary Appendix. (Supplementary Materials)

\section{References}

[1] J. H. Cochrane, "Presidential address: discount rates," The Journal of Finance, vol. 66, pp. 1047-1108, 2011.

[2] K. Hou, H. Mo, C. Xue, and L. Zhang, "Which factors?" Review of Finance, vol. 23, no. 1, pp. 1-35, 2018.

[3] F. E. Racicot and W. F. Rentz, "A panel data robust instrumental variable approach: a test of the new Fama-French fivefactor model," Applied Economics Letters, vol. 24, pp. 410-416, 2017.

[4] F. E. Racicot, W. F. Rentz, and R. Théoret, "Testing the new fama and French factors with illiquidity: a panel data investigation," Finance, vol. 39, pp. 45-102, 2018.

[5] F. E. Racicot, W. F. Rentz, D. Tessier, and R. Théoret, "The conditional Fama-French model and endogenous illiquidity: a robust instrumental variables test," PLoS One, vol. 14, no. 9, Article ID e0221599, 2019.

[6] E. F. Fama and K. R. French, "A five-factor asset pricing model," Journal of Financial Economics, vol. 116, pp. 1-22, 2015.

[7] L. Pástor and R. F. Stambaugh, "Liquidity risk and expected stock returns," Journal of Political Economy, vol. 111, pp. 642-685, 2003.

[8] F. Qiao, "Replicating anomalies in China," SSRN, vol. 33, no. 5, pp. 2019-2133, 2019.

[9] K. Hou, C. Xue, and L. Zhang, "Replicating anomalies," Review of Financial Studies, 2018.

[10] E. F. Fama and K. R. French, "Choosing factors," Journal of Financial Economics, vol. 128, pp. 234-252, 2018.

[11] G. Feng, S. Giglio, and D. Xiu, Taming the Factor Zoo: A Test of New Factors, National Bureau of Economic Research, Cambridge, MA, USA, 2019.

[12] G. X. Hu, C. Chen, Y. Shao, and J. Wang, "Fama-French in China: size and value factors in Chinese stock returns," International Review of Finance, vol. 19, pp. 3-44, 2019.

[13] F. Jiang, X. Qi, and G. Tang, "Q-theory, mispricing, and profitability premium: evidence from China," SSRN Electronic Journal, vol. 87, pp. 135-149, 2018.

[14] C. Cheung, G. Hoguet, and S. Ng, "Value, size, momentum, dividend yield, and volatility in China's a-share market," Journal of Portfolio Management, vol. 41, pp. 57-70, 2014.

[15] J. Liu, R. F. Stambaugh, and Y. Yuan, "Size and value in China," Journal of Financial Economics, vol. 134, pp. 48-69, 2019.

[16] Y. Han, A. He, D. Rapach, and G. Zhou, "Expected stock returns and firm characteristics: E-LASSO, assessment, and implications," SSRN, 2019.

[17] J. Freyberger, A. Neuhierl, and M. Weber, "Dissecting characteristics nonparametrically," The Review of Financial Studies, vol. 33, 2019.

[18] E. F. Fama and K. R. French, "Common risk factors in the returns on stocks and bonds," Journal of Financial Economics, vol. 33, pp. 3-56, 1993.

[19] N. Jegadeesh and S. Titman, "Return to buying winners and selling losers: implication for stock market efficiency," The Journal of Finance, vol. 48, pp. 65-91, 1993.

[20] K. Hou, C. Xue, and L. Zhang, "Digesting anomalies: an investment approach," The Review of Financial Studies, vol. 28, no. 3, pp. 650-705, 2015.
[21] R. F. Stambaugh and Y. Yuan, "Mispricing factors," Review of Financial Studies, vol. 30, pp. 1270-1315, 2017.

[22] K. D. Daniel, D. A. Hirshleifer, and L. Sun, "Short- and longhorizon behavioral factors," Review of Financial Studies, vol. 33, pp. 1673-1736, 2020.

[23] J. Shanken, "On the estimation of beta-pricing models," Review of Financial Studies, vol. 5, pp. 1-33, 1992.

[24] J. Shanken, M. R. Gibbons, and S. A. Ross, "A test of efficiency of a given portfolio," Econometrica, vol. 57, pp. 1121-1152, 1989.

[25] W. K. Newey and K. D. West, "A simple, positive semidefinite, heteroskedasticity and autocorrelation consistent covariance matrix," Econometrica, vol. 55, pp. 703-708, 1987.

[26] Cochrane, Asset Pricing (Revised Edition), Princeton University Press, Princeton, NJ, USA, 2009.

[27] W. Ferson, Empirical Asset Pricing: Models and Methods, The MIT Press, Cambridge, MA, USA, 2019.

[28] E. Ghysels and M. Marcellino, Applied Economic Forecasting Using Time Series Methods, Oxford University Press, Oxford, UK, 2018.

[29] B. Efron, T. Hastie, I. M. Johnstone, and R. Tibshirani, "Least angle regression," Annals of Statistics, vol. 32, pp. 407-499, 2004.

[30] J. H. Friedman, T. Hastie, H. Hofling, and R. Tibshirani, "Pathwise coordinate optimization," Annals of Applied Statistics, vol. 1, pp. 302-332, 2007.

[31] C. S. Asness, A. Frazzini, and L. H. Pedersen, Quality Minus Junk, Social Science Electronic Publishing, Waltham, MA, USA, 2013.

[32] W. Kang and H. Zhang, "Measuring liquidity in emerging markets," Pacific-Basin Finance Journal, vol. 27, pp. 49-71, 2014.

[33] Y. Hu and M. Gu, "Buffett's alpha: evidence from China stock market," Management World, vol. 8, pp. 41-54, 2018. 